\title{
Cost and Time Differences between Three Types of Restorations for Primary Teeth: Amalgam, Composite and Glass-Ionomer Cement.
}

Hanthao Thi Phan

University of Utah, School of Dentistry

John M. Powers

Dental Consultants Inc

Franklin Garcia-Godoy

University of Tennessee Health Science Center College of Dentistry

Timothy Brown

University of California Berkeley School of Public Health

Lilliam Marie Pinzon ( $\nabla$ Lilliam.Pinzon@hsc.utah.edu )

University of California, San Francisco https://orcid.org/0000-0002-3532-7201

Research article

Keywords: Minimally invasive, primary teeth, amalgam, composite, atraumatic restorative treatment, caries, cost effect, SAR-CoV-2

Posted Date: October 16th, 2020

DOI: https://doi.org/10.21203/rs.3.rs-75537/v1

License: (c) (1) This work is licensed under a Creative Commons Attribution 4.0 International License. Read Full License 


\section{Abstract}

Background: Early Childhood Caries is the most prevalent chronic disease among children in the United States. Three common approaches for treatment of dental caries in general population include: amalgam, composite, and glass ionomer. The purpose of this study was to measure the treatment cost differences for amalgam, composite, and atraumatic restorative treatment (ART) restorations of primary teeth and evaluate possible factors that could influence the cost of treatment.

Methods: This cross-sectional study randomly selected data of 120 restorations from a clinical observational study of the restoration of primary teeth in children aged $5-10$ years old. The 120 selected restorations in primary teeth, half with two surfaces and half with three surfaces, were performed by two operators at the Asian Health Center and Centro American Resources Center in California. Data were analyzed using multivariable linear regression.

Results: Performing ART was found to take 7.8 minutes less than amalgam $(p<0.01)$ and 19.0 minutes less than composite. ART was found to be $6.4 \%(p=0.01)$ less costly than amalgam and $62.4 \%(p<0.01)$ less costly than composite.

Conclusions: ART was found to be the least costly treatment compared to amalgam and composite restoration procedures. ART also required the shortest time during the clinical procedure.

Trial Registration: UCSF CHR Number: H55840-32823-02

\section{Background}

Early Childhood Caries (ECC) is the most prevalent chronic disease among children in the United States; this public health issue is on the rise, according to recent reports.[1, 2] Underserved children and those who come from economically disadvantaged backgrounds face a severe risk to their well-being because of ECC.[2] Nationally, ECC prevalence (any decayed, extracted or filled teeth among 2-5 year-olds) in $1988-1994$ was $24 \%$ and rose to $28 \%$ in $1999-2004 .[1,2]$

Longitudinal studies have reported that preschool age children with ECC have a higher risk for caries and dental problems in their permanent teeth later in life, affecting psychosocial well-being, growth, and development.[3-7] The adverse health effects, economic costs, disparities by race/ethnicity, and income posed by ECC demonstrate a compelling need for preventive strategies.[2]

Two-thirds of all children in the state of California suffer from poor oral health by the time they reach third grade.[8] That is roughly 6.3 million children. In 2007, approximately 7 percent of California children missed school due to a dental problem (not including time for a cleaning or routine check-up). In addition, approximately 6 percent of all California adults between the ages of 21 and 65 missed work or school because of a dental problem (not including missed time for cleaning or a check-up). $[9,10]$ There were more than 83,000 visits to California hospital emergency departments for preventable dental conditions 
in 2007.[11] Lastly, 73 percent of California adults are unaware that the disease, which causes tooth decay and dental caries, is an infection and spreads from person to person.[12]

Three common approaches for treatment of dental caries in general population include: amalgam, composite, and glass ionomer (atraumatic restorative treatment (ART)) restorations for which The American Academy of Pediatric Dentistry established guidelines.[13-15]

ART was initially tested in Tanzania (Africa) in the mid 1980s and was presented to the World Health Organization on World Health Day in 1994 as a new approach to treat dental caries.[16] ART was created to treat special population groups such as refugees and poor communities that could not otherwise afford dental care. The ART technique consists of excavation and removal of the softest portions of carious lesions using only hand instruments and restoration of the cavities, pits and fissures with glass ionomers.[16] ART has also been shown to be a valuable treatment for underprivileged school children not treated in conventional dental environments.[17]

In previous clinical trials, the success and failure rates (longevity) of class II restorative treatments (amalgam, composite and glass ionomer) in children with primary teeth were compared. A key conclusion of these trials was that no caries were present on a cavo-surface margin or around glass ionomer restorations in primary teeth.[18] A recent meta-analysis concluded that ART restorations on single surfaces of primary and permanent teeth using a high-viscosity glass ionomer resulted in high survival rates.[19] In general, the success rates of ART restorations are high, especially for single-surface restorations. Other advantages of ART compared to amalgam and composite include caries preventive effects, decrease in cost and time for the clinician, acceptance by patients, and the effective treatment of carious lesions with apparent remineralization.[16]

There have been no studies of ART restorations conducted in the US. One reason for this may be the perception that the ART technique is not part of the accepted standard of care. While ART is considered a useful aid for use in undeveloped countries and for communities that cannot afford standard dental care, [20] ART is not currently considered to meet the American standard of dental care as there is no specific ADA (American Dental Association) code for ART in order to charge it for reimbursement.

In the U.S. and specifically in California, there are numerous vulnerable populations where the use of ART might prove extremely helpful. These populations include those that cannot afford dental care $(12.8 \%$ persons living at and below the poverty level in California and $11.8 \%$ in the U.S. as of 2018), young children who cannot tolerate local anesthesia, Native Americans living on reservations, cancer patients with xerostomia as a secondary effect of cancer treatment, the elderly confined to nursing homes, and those with physical and mental disabilities (nearly 2,700,000 in California under age 65 years and nearly $28,000,000$ in US as of 2018).[21]

Because of its minimally invasive technique, ART would be a good approach for treatment of dental caries during pandemics. In March 2020, the World Health Organization (WHO) declared the coronavirus disease (COVID-19) outbreak a pandemic.[22] As of July 04, 2020, there were 2.2 millions confirmed 
cases and 119, 318 deaths in the U.S. due to COVID-19.[23, 24] SARS-CoV-2, the virus that cause COVID19 , is primarily transmitted through respiratory droplets and has been shown to persist in aerosol for hours.[25] Conventional restorative techniques require the use of dental handpieces and burs that generate visible spray that contains droplets of saliva, blood and microorganism. On other hand, ART requires manual instrument that is minimally invasive and generates much less aerosol. The Centers for Disease Control and Prevention (CDC) has recommended that dentists prioritize minimally invasive/atraumatic restorative techniques, such as ART, and avoid dental procedures that generate aerosol whenever possible.[25]

This cross-sectional study evaluated the cost difference of three dental restorative procedures in highcaries-risk children from lower socio-economic status households, many of whom rely on public assistance and all of whom are eligible for Denti-Cal (Medicaid) coverage. Our population was treated at the Asian Health Center (AHC) in Oakland, California, and Centro American Resources Center (CARECEN) in San Francisco, California.

The null hypotheses were:

1. There are no differences in the time to provide the different restorative procedures (amalgam, composite, and ART) performed at the AHC Dental Clinic and CARECEN by two clinicians after taking into account the characteristics of the teeth treated, and

2. There are no differences in the cost of the different restorative procedures (amalgam, composite, and ART) performed at the AHC Dental Clinic and CARECEN by two clinicians after taking into account the characteristics of the teeth treated.

\section{Materials And Methods}

This cross-sectional study was part of an clinical observational study that was approved by the institutional review board (IRB) of the University of California. Data of 120 restorations included in this cross-sectional study were randomly selected from 209 participants in the clinical observational study following the inclusion and exclusion criteria approved by IRB. Parental written informed consent was obtained in Cantonese, Mandarin, Vietnamese, Korean, Chiuchow, English, or Spanish as appropriate and child assent obtained for children age 7 and older. Eligible children were healthy, from 5 to 11 years-old at enrollment, and registered as patients at AHC Dental Clinic in Oakland, California and CARECEN in San Francisco, California. At enrollment, the children had caries in at least one primary molar (1 to 3 surfaces cavitated) that could be treated with ART, composite, or amalgam restoration. All the children with any mental or physical incapacity, uncooperative or behaviorally unsuited for outpatient dental treatment, children with cleft lip and/or palate, children with immune compromised conditions or on xerostomic medications that might affect the oral flora were ineligible. Children with teeth receiving crowns, pulpotomy or pulp cap procedures were also ineligible.

During the recruitment and enrollment of the clinical observational study, research assistants (RA) were trained for the recruitment of the participants. The RAs and PI presented the study to the parents and the 
participants using the booklet and a reading story to describe the study. Permission and consent from the parent/guardian was obtained in order to collect demographic and treatment information (including radiographic) from the participant's dental chart at baseline and follow-up $(6,12,18$ and 24-month followup visit). A clinical and photographic evaluation of selected restored teeth was also obtained at each follow up visit. Recruited and enrolled study participants from clinical observational study were treated with single and multiple-surface ART, composite, or amalgam restorations. This selection of restoration type was determined by the clinician without influences from the research team. Restorations were followed by a modified version of Ryge Criteria for Direct Clinical Evaluation protocol (Fig. 1) to assess a) caries recurrence, $b$ ) restoration retention, and $c$ ) restoration marginal integrity over time (baseline and follow ups, at 6, 12, 18 and 24-months post restoration placement) (Fig. 1).

Among 120 restorations selected for this cross-sectional study, sixty restorations with two surfaces (20 amalgam, 20 composite and 20 ART) and sixty with three surfaces (20 amalgam, 20 composite and 20 ART) were performed by two operators at the AHC and CARECEN. The total times for 120 procedures were recorded by one researcher (LMP) using a standard chronometer. The time starting point included the preparation of the cavity with a hand piece for amalgam and composite restorations and/or cavity preparation using hand instruments for ART. Also included were the restorative steps required for the different restorative procedures such as conditioners, etching, priming, and/or bonding, the placement of the restorative material, and finally polishing, if necessary.

The two dentists participating in the study were classified as DDS1 and DDS2. The estimated annual salaries were $\$ 120,000$ for DDS1, $\$ 100,000$ for DDS2, and $\$ 40,000$ for the dental assistant. To calculate labor costs per hour for each provider, each annual salary was divided by 2000 under the assumption that each worked 2000 hours per year. The cost of materials for two-surface restorations using amalgam, composite, and ART were $\$ 4, \$ 34$, and $\$ 10$, respectively. The cost of materials for three-surface restorations using amalgam, composite, and ART were $\$ 6, \$ 51$, and $\$ 15$, respectively. Overhead cost was a fixed cost and was thus economically irrelevant for cost comparison purposes.

Time data were analyzed using ordinary least squares. Cost data were analyzed by following a standard algorithm from the health economics literature.[26] The appropriate cost model was found to be a generalized linear model with a Poisson distribution and a log link. Standard errors were corrected for arbitrary forms of heteroscedasticity in all models. Each model included the same set of independent variables: restoration type (amalgam, composite, or ART), tooth type (7 types), number of surfaces $(1,2$, or 3 surfaces), and dental provider (1 or 2 ).

\section{Results}

Table 1 presents mean treatment times and standard deviations for dentist one (DDS1) and dentist two (DDS2) for amalgam (AMAL), composite (COMP) and atraumatic restoration (ART). Table 2 presents descriptive statistics for all variables used in the multivariable regression. 
Table 1

Treatment time (minutes) difference of amalgam, composite and ART restorations between DDS1 and DDS2.

\begin{tabular}{|llllllll|}
\hline & \multicolumn{3}{c}{ DDS1 } & & \multicolumn{3}{c|}{ DDS2 } \\
\hline & Amalgam & Composite & ART & Amalgam & Composite & ART \\
\hline Median & 23.5 & 36.0 & 16.0 & 24.5 & 36.0 & 17.5 \\
\hline Mean & 23.1 & 34.1 & 15.4 & 24.2 & 35.8 & 16.4 \\
\hline Standard Deviation & 3.3 & 4.8 & 3.3 & 2.7 & 3.2 & 3.5 \\
\hline
\end{tabular}

Table 2

Descriptive Statistics (120 observations)

\begin{tabular}{|lll|}
\hline Variables & Mean & Standard Deviation \\
\hline Total Cost (\$) & 47 & 25 \\
\hline Total time (minutes) & 24.8 & 8.6 \\
\hline Restoration Type, \% & & \\
\hline Amalgam & 33.3 & - \\
\hline Composite & 33.3 & - \\
\hline ART & 33.3 & - \\
\hline Tooth type, \% & & \\
\hline 1 & 8.3 & - \\
\hline 2 & 14.2 & - \\
\hline 3 & 15.8 & - \\
\hline 4 & 12.5 & - \\
\hline 5 & 12.5 & - \\
\hline 6 & 13.3 & - \\
\hline 7 & 15.0 & - \\
\hline Number of surfaces, \% & & \\
\hline 2 & 50 & - \\
\hline 3 & 50 & - \\
\hline
\end{tabular}

The multivariable regression results are presented in Table 3. The reference group is amalgam restorations, two surfaces, and DDS1. Composite restorations took approximately 11 minutes longer than amalgam restoration and ART restoration took approximately 8 minutes less than amalgam restoration. 
This result was based on controlling for tooth type, number of surfaces, and the particular dentist performing the restoration. This difference in time and the differences in the cost of materials were the main determinants of the difference in total cost between each type of restoration. While composite restorations cost $149 \%$ of amalgam restorations, ART restorations cost $6.4 \%$ less than amalgam restorations.

Table 3

Multivariate Regression Results (120 observations)

\begin{tabular}{|c|c|c|c|c|}
\hline \multirow[t]{2}{*}{ Variables } & \multicolumn{2}{|l|}{ Total Time } & \multicolumn{2}{|l|}{ Total Cost } \\
\hline & Coefficient & $z$-statistic & Coefficient & $z$-statistic \\
\hline \multicolumn{5}{|c|}{ Restoration Type (reference: Amalgam) } \\
\hline Composite & $11.210^{*}$ & 13.82 & $149.179 *$ & 46.08 \\
\hline ART & $-7.761^{\star}$ & -10.97 & $-6.387^{\star}$ & -2.49 \\
\hline \multicolumn{5}{|c|}{ Tooth type (reference: 1) } \\
\hline 2 & -0.815 & -0.70 & -2.371 & -0.84 \\
\hline 3 & -1.004 & -0.84 & -3.343 & -1.17 \\
\hline 4 & 0.296 & 0.25 & 0.200 & 0.07 \\
\hline 5 & -1.175 & -0.95 & -2.955 & -1.08 \\
\hline 6 & 0.287 & 0.24 & 1.308 & 0.50 \\
\hline 7 & -0.018 & -0.02 & -0.499 & -0.20 \\
\hline \multicolumn{5}{|c|}{ Number of surfaces (reference: 2) } \\
\hline 3 & $1.740^{\star}$ & 2.73 & $22.140 *$ & 12.34 \\
\hline \multicolumn{5}{|c|}{ Dentist (reference: 1) } \\
\hline 2 & -1.258 & -1.92 & $5.127^{\star}$ & 3.26 \\
\hline \multicolumn{5}{|c|}{ Total Time estimated using ordinary least squares. } \\
\hline \multicolumn{5}{|c|}{$\begin{array}{l}\text { Total Cost estimated using generalized linear model with Poisson distribution and log link (all } \\
\text { coefficients transformed to percentages: } 100 \text { (exp(parameter)-1) }\end{array}$} \\
\hline \multicolumn{5}{|c|}{ All standard errors are robust to heteroscedasticity } \\
\hline \multicolumn{5}{|c|}{ Reference group: amalgam restorations, tooth type 1, two surfaces, and DDS1 } \\
\hline${ }^{\star} p \leq .01$ & & & & \\
\hline
\end{tabular}

Null hypothesis 1 was rejected because there were statistical differences $(p \leq 0.01)$ in the average times to perform the different restorative procedures (amalgam, composite, and ART) by two clinicians after 
controlling for confounding factors. ART was shown to have the shortest clinical time, followed by amalgam and finally composite restorations.

Null hypothesis 2 was rejected because there were statistical differences $(p \leq 0.01)$ in the average cost of the different restorative procedures performed by two clinicians after controlling for confounding factors. The total cost was determined based on the cost of clinical time and material. ART was shown to have lowest total cost, followed by amalgam and finally composite restoration.

\section{Discussion}

In this study, the selection criteria for the different treatments were equal in order to have consistent values that can be comparable to each other. This selection of restoration type was determined by each clinician without influences from the research team. The mean treatment times for amalgam restorations with two and three surfaces were 23.1 and 24.2 minutes, respectively. The mean treatment times for composite restorations with two and three surfaces were 34.1 and 35.8 minutes, respectively. The mean treatment times for ART restorations with two and three surfaces were 15.4 and 16.4 minutes, respectively. The clinical time taken to restore teeth with composite was relatively long compared to amalgam and ART. A possible explanation might be the sticky nature of the composite that resulted in some corrections and finishing having to be performed in the mouth.

Other treatment studies found that the mean treatment times was 37 minutes for standard three-surface amalgam restorations,[26] 42 minutes for three-surface amalgam restorations on molars,[27] and 60 minutes for extensive amalgam restorations on molars.[28] It should be mentioned that all reported treatment times for the amalgam restorations included polishing. The mean treatment time for threesurface direct composite restorations was 37 minutes.[29] When treating children with direct composite restorations and amalgam restorations, there was a clear trend for the placement time of posterior composite restorations to be greater than that for amalgam.[30] These findings agreed with the findings in our study in which amalgam restorations had shorter clinical time than composite restorations. ART clinical time in our study with a mean of 16.4 minutes for three-surface restoration was shown to be shorter than the clinical time required for amalgam and composite restorations in our study and other studies. The reason for shorter clinical time of ART probably due to the thermal expansion of glass ionomer that is similar to natural teeth and glass ionomer can be placed in a single increment.[31] This quality gives us advantage in reducing working time.

Our study also showed that the treatment cost of ART restorations were lower than those of amalgam and composite restorations. The lower cost of ART restorations provides an opportunity for vulnerable populations who cannot afford dental care to treat their dental caries. Moreover, fluoride released from glass ionomer promotes remineralization and thus helps prevent recurrent caries.[31] These factors together make of ART an acceptable and effective treatment of dental caries for vulnerable populations who lack of access and finances for dental care. 
ART restoration is not only beneficial to vulnerable populations, but also would help general populations to obtain their dental care regrading to the current situation of COVID 19 in the U.S. The COVID 19 pandemic has been posing a severe negative impact on the U.S. economy. It has caused 17.8 million people unemployed as of June 2020.[32] The jobless rate and the number of unemployment were increased by 7.6 percentage points and 12.0 million, respectively, since February, the time before the pandemic.[32] Unemployment has caused people to lose their health insurance and dental insurance which are usually provided by employers. The lack of dental insurance prevents people from accessing their dental care due to the high cost of conventional treatments. With its low cost of treatment, ART would allow the general population to continue their dental care. Moreover, the ART is minimally invasive and produces less aerosols.[25] This quality of ART helps minimizing the transmission of SAR-CoV-2 in dental facility and maintaining healthy environment for dental professionals and patients.

Limitations to this analysis include the relative costs of dentists and dental assistants. Since differences in costs are proportional to time spent performing the procedures, the lower the salaries of the dentists and the dental assistant are, the smaller the difference in cost will be between ART and amalgam restorations.

Many cost-effectiveness and cost-benefit studies have been conducted in order to guide present and future resource allocation decisions as well as the development of codes used to identify different diagnoses, treatment plans, and reimbursement. In fact, some health care decision makers have not accepted some analyses because a critical factor or issue has been omitted. For this reason, clinical translational studies must integrate different disciplines (general dentistry, public health, material sciences, pediatrics, clinical research, policy, economics) in order to cover the possible issues that decision makers consider when evaluating scientific reports related to the need for changes in the dentistry standard of care in the U.S.

A wide variety of international studies have shown that ART has very good recurrent caries prevention and acceptable retention compared with traditional amalgam restorations.[26, 33] In addition, caries removal with ART is ultraconservative and retains much more tooth structure than traditional methods.

Any decision regarding the appropriate procedure to use in a given situation is based on both clinician judgment and experience. Such decisions should also consider objective evidence, such as the above findings. Compared to amalgam and composite restoration, ART can be performed faster, on average, and for a lower average cost.

For all these reasons, it is important to continue performing studies of ART in order to further illustrate the value of changing the standard of care in the US. This cost analysis is a pilot study that can help in the design of future studies with larger sample sizes that can be used by policy makers who lead the development of new rules for standards of care in pediatric dentistry and for efficient planning in dental practice. This pilot study could have potential impacts in dental practice, patient management policies, and public health. 


\section{Conclusions}

- Relative to amalgam and composite restoration, ART was the shortest clinical procedure.

- ART was a cost-effective procedure that should be studied further as a candidate for inclusion in the US standard of care for pediatric dentistry.

\section{Abbreviations}

ADA: American Dental Association

AHC: Asian Health Center

AMAL: Amalgam

ART: Atraumatic restorative treatment

CARECEN: Centro American Resources Center

CDC: Centers for Disease Control and Prevention

COMP: Composite

ECC: Early Childhood Caries

IRB: Institutional Review Board

WHO: World Health Organization

\section{Declarations}

\section{Ethics approval and consent to participate:}

The study was approved by Institutional Review Board (IRB) of University of California, USA. The study was conducted following the IRB guideline and according to Declaration of Helsinki. The study was undertaken with the understanding and written informed consent from parents of participants. The participants in this study are children aged 5-10 years old. All the parents of the participants signed a written informed consent before the treatment of the participants. Children aged 7 or older also signed an additional written assent form.

\section{Consent for publication:}

Not applicable 


\section{Availability of data and materials:}

The datasets used and/or analyzed during the current study are available from the corresponding author on reasonable request.

\section{Competing interest:}

The authors declare that they do not have any conflict of interest relationships.

\section{Funding:}

This project was supported by U.S. Department of Health and Human Services, National Institutes of Health, National Institute of Dental and Craniofacial Research K23/NIH/NIDCR DE020091 (PI: Lilliam M Pinzon). GC America Inc. provided glass ionomer material.

\section{Authors' contributions:}

All authors contributed to the study conception and design. Material preparation, data collection and analysis were performed by HTP, TB, JMP, FGG, and LMP. The first draft of the manuscript was written by LMP and all authors commented on previous version of the manuscripts. All authors read and approved the final manuscript.

\section{Acknowledgments:}

Not applicable

\section{Authors' information:}

LMP is currently Section Head of Public Health and Global Health, Vice-President AADR Utah section, and Associate Professor at the University of Utah School of Dentistry. She is working in clinical translational research with emphasis in Clinical Research, Dental Materials analysis in vivo and in vitro, and focusing on solutions to improve oral health for disadvantaged populations, nationally and internationally. Her current work in Clinical Translational Research, community work and in-vitro studies allow her to have a wide network of professionals that collaborate with her nationally and internationally trying to find solutions to improve public health issues related to oral health for disadvantaged populations and cost effective treatments to treat different kind of populations. She has been working JMP, TB, FGG, and HTP for a long time and their studies focusing on the minimally invasive techniques in dentistry with the aim to improve oral health and access to dental care for vulnerable populations. JMP is a Professor at 
University of Texas School of Dentistry, Senior Vice President at Dental Consultants Inc., and an Editor at the Dental Advisor. TB is Associate Director for Research at Berkeley Center for Health Technology and an Associate Adjunct professor of Health Economics, School of Public Health, University of California, Berkeley. FGG is a Professor in Department of Bioscience Research, Director of Bioscience Research Center and Clinical Research at College of Dentistry, University of Tennessee Health Science Center. HTP joined LMP laboratory several years ago during her undergraduate training at the University of Utah and became research assistant after her graduation to continue working on national and international global health projects while preparing for dental school.

\section{References}

1. Leverrett DH, Proskin HM, Featherstone JD, Adair SM, Eisnberg AD, Mundorff-Shrestha SA. Caries risk assessment in a longitudinal discrimination study. J Dent Res 1993;72(2):538-543.

2. Dye BA, Li X, Beltran-Aguilar ED. Selected oral health indicators in the United States 2005-2008. NCHS Data Brief, 2012;(96):1-8

3. Wesenberg G, Hals E. The in vitro effect of a glass ionomer cement on dentin and enamel walls. An electron probe and microradiographic study. J Oral Rehabil 1980;7(1):35-42.

4. Sennou HE, Lebugle AA, Gregoire GL. X-ray photoelectron spectroscopy study of the dentin-glass ionomer cement interface. Dent Mater 1999;15(4):229-237.

5. Massara MLA, Alves JB, Brandao PRG. Atraumatic restorative treatment: clinical, ultrastructural and chemical analysis. Caries Res 2002;36(6):430-436.

6. Yoshida Y, Van Meerbeek B, Nakayama Y, Snauwaert J, Hellemans L, Lambrechts P. Evidence of chemical bonding at biomaterials-hard tissue interfaces. J Dent Res 2000;79(2):709-714.

7. Couthinho E, Yoshida Y, Inoue S, Fukuda R, Snauwaert J, Nakayama Y, et al. Gel Phase formation at resin-modified glass ionomer/tooth interfaces. J Dent Res 2007;86(7):656-661

8. Dental Health Foundation. Mommy, It Hurts to Chew: The California Smile Survey: An Oral Health Assessment of California's Kindergarten and 3rd Grade Children. 2006. Available at: https://www.centerfororalhealth.org/wp-content/uploads/2018/11/Mommy-lt-Hurts-ToChew.compressed.pdf

9. UCLA Center for Health Policy Research. California Health interview survey (CHis) [dataset]. 2003.

10. UCLA Center for Health Policy Research. California Health interview survey (CHis) [dataset]. 2007.

11. California HealthCare Foundation. Emergency Department Visits for Preventable Dental Conditions in California. May 2009. Available at https://www.chcf.org/wp-content/uploads/2017/12/PDFEDUseDentalConditions.pdf

12. Pourat N . Drilling down: access, affordability, and consumer perceptions in adult dental health[Internet]. Oakland (CA): California HealthCare Foundation. 2008. Available from: http://www.chcf.org/publications/2008/11/drilling-down-access-affordability-and-consumerperceptions-in-adult-dental-health 
13. Fuks AB. The use of amalgam in pediatric dentistry. Pediatr Dent 2002;24(5):448-455.

14. Donly KJ, García-Godoy F. The use of resin-based composite in children. Pediatr Dent 2002;24(5):480-488

15. Berg JH. Glass ionomer cements. Pediatr Dent 2002;24 (5):430-438

16. Frencken JE, Leal SC, Navarro MF. Twenty-five-year atraumatic restorative treatment (ART) approach: a comprehensive overview. Clin Oral Investig. 2012;16(5):1337-1346.

17. de Amorim RG, Leal SC, Frencken JE. Survival of atraumatic restorative treatment (ART) sealants and restorations: a meta-analysis. Clin Oral Investig. 2012;16(2):429-441.

18. Ferreira JM, Pinheiro SL, Sampaio FC, de Menezes VA. Caries removal in primary teeth-a systematic review. Quintessence Int. 2012;43(1):e9-15.

19. van 't Hof MA, Frencken JE, van Palenstein Helderman WH, Holmgren CJ. The atraumatic restorative treatment (ART) approach for managing dental caries: a meta-analysis. Int Dent J 2006;56(6):345351.

20. Frencken JE, Phantumvanit P, Pilot T, Songpaisan Y, van Amerogen E. Manual for the atraumatic restorative treatment approach to control dental caries. 3a ed. WHO Collaborating Center for Oral Services Research. Groningen, 1997.

21. S. Census Bureau. QuickFacts: Califonia; United States [Internet]. 2019. Available in https://www.census.gov/quickfacts/fact/table/CA,US

22. Virtual press conference on COVID-19 - 11 march 2020 [Document]. World Health Organization; 2020. Available inhttps://www.who.int/docs/default-source/coronaviruse/transcripts/who-audioemergencies-coronavirus-press-conference-full-and-final-11 mar2020.pdf

23. COVIDView: A weekly surveillance summary of U.S. COVID 19 Activity. Week 27, ending July 4, 2020 [Internet]. Centers for Disease Control and Prevention. 2020. Available in https://www.cdc.gov/coronavirus/2019-ncov/covid-data/covidview/index.html

24. Provisional death counts for coronavirus disease 2019 (COVID-19) [Internet]. Centers for Disease Control and Prevention. 2020. Available in https://www.cdc.gov/nchs/nvss/vsrr/COVID19/index.htm

25. Interim infection prevention and control guidance for dental settings during the COVID-19 response [Internet]. Centers for Disease Control and Prevention. 2020. Available in https://www.cdc.gov/coronavirus/2019-ncov/hcp/dental-settings.html\#EquipmentConsiderations

26. Manning, W. G. and J. Mullahy. 2001. Estimating log models: to transform or not to transform? J Health Economics 2001;20(4):461-494.

27. Advokaat JGA, Van ' $t$ Hof MA, Akerboom HBM, Borgmeijer PJ : Treatment times of amalgam restoration Community Dent Oral Epid emiol 1992; 20: 200- 203.

28. Hendriks F. H. J., Leztel H. and Vrijhoef M. M. A. (1985) Cost benefit analysis of direct posterior restorations. Community Dent Oral Epidemiol 1985;13(5):256-259.

29. Plasmans P. J. J. M. and van't Hof M. A. (1987) Treatment time analysis for extensive amalgam restorations. Community Dent Oral Epidemiol 1987;15(4):192-196. 
30. Dilley DC, Vann WF Jr, Oldenburg TR, Crisp RM. Time required for placement of composite versus amalgam restorations. J Dent Child. 1990;57(3):177-183

31. Ladewig NM, Sahiara CS, Yoshioka L, Olegário IC, Floriano I, Tedesco TK, et al. Efficacy of conventional treatment with composite resin and atraumatic restorative treatment in posterior primary teeth: Study protocol for a randomised controlled trial. BMJ Open. 2017;7(7):1-6.

32. US Bureau of Labor Statistics. June 2020: Employment situation news release and COVID 19 impact summaries [Internet]. Bureau of Labor Statistics, U.S. Department of Labor. 2020. Available in https://www.bls.gov/news.release/archives/empsit_07022020.htm

33. Mickenautsch S, Yengopal V, Leal SC, Oliveira LB, Bezerra AC, Bönecker M. Absence of carious lesions at margins of glass-ionomer and amalgam restorations: a meta- analysis. Eur $\mathrm{J}$ Paediatr Dent 2009;10(1):41-46.

\section{Figures}

\begin{tabular}{|l|l|l|}
\hline Pte\# & $\begin{array}{l}\text { Scoring } \\
\text { Criteria }\end{array}$ & Marginal Adaptation \\
\hline & 0 & $\begin{array}{l}\text { After the visual and tactile examination using an explorer } \\
\text { across the margins. The restoration looks well adapted and } \\
\text { close to the surface of the tooth }\end{array}$ \\
\hline & 1 & $\begin{array}{l}\text { After the visual and tactile examination using an explorer } \\
\text { across the margins. There was tactile evidence of a gap at } \\
\text { a marginal crevice. The explorer was lightly caught in both } \\
\text { directions. Dentin was not visible }\end{array}$ \\
\hline & 2 & $\begin{array}{l}\text { After the visual and tactile examination using an explorer } \\
\text { across the margins. There was visible evidence of a gap. } \\
\text { The explorer was caught in both directions and penetrated } \\
\text { a marginal crevice. Dentin was not visible }\end{array}$ \\
\hline & 3 & The restoration was fractured or lost \\
\hline & 0 & $\begin{array}{l}\text { Anatomical form } \\
\text { anatomy restoration was continuous with the existing tooth }\end{array}$ \\
\hline & 1 & $\begin{array}{l}\text { The restoration was not continuous with the existing tooth } \\
\text { anatomy and required replacement }\end{array}$ \\
\hline & Caries at the cavosurface margin \\
\hline & 0 & No caries was present on a cavosurface margin \\
\hline & 1 & Caries was present on a cavosurface margin \\
\hline
\end{tabular}

-Type of tooth: RU, LU, RL, LL

-Tooth Lesion depth:

-Type of cavity:

-Type of Jaw: Mandible or Maxilar

-Type of Material: Amalgam or GIC

-RX:

-Photo:

Pte\#:

Score: 
Modified version of Ryge Criteria for Direct Clinical Evaluation protocol

\section{Supplementary Files}

This is a list of supplementary files associated with this preprint. Click to download.

- STROBEchecklistv4combined.doc 